\title{
LA AGRICULTURA CELULAR: Del laboratorio a su mesa
}

\section{Por: Lic. Karen lbarra \\ Docente Nutrición UCIMED}

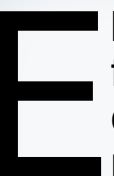

término "agricultura celular" puede no sonar muy familiar, sin embargo, existe la posibilidad de que, en unos años, sea la forma en que se produzca la mayoría de nuestros alimentos. Imagine que va al supermercado y en el estante encuentra un paquete de tortas de carne con la leyenda "Ningún animal fue dañado en la elaboración de este producto", ¿es esto posible? Sí, gracias a los avances en la ciencia y la tecnología, esto se puede lograr.

Ahora bien, ¿qué es la agricultura celular? Ésta es una tecnología que permite cultivar carne y otros productos agrícolas en un biorreactor, en lugar de una granja o finca ganadera. Esto quiere decir, que se cultiva el tejido muscular a partir de las células madre de un animal, en otras palabras, permite que ingenieros cultiven tejido muscular in vitro, sin necesidad de sacrificar animales en el proceso.

Aunque esto había sido posible desde hace mucho tiempo, fue hasta el año 2013 donde Mark Post, un científico de la Universidad de Maastricht en Holanda, creó la primera hamburguesa hecha de células madre bovinas.

Por ahora el costo de esta tecnología es elevado, para poder cultivar el prototipo de la torta de carne de Mark Post, se requirió una inversión cercana a los $\$ 300,000$. Sin embargo, los ingenieros que trabajan en esta tecnología, afirman que eventualmente puede ser una forma más rentable de producir carne y otros productos agrícolas, que en fincas 0 granjas tradicionales.

Los promotores de esta tecnología indican que la agricultura celular tiene grandes beneficios, por ejemplo, en la salud. En la carne cultivada en laboratorios se puede controlar el tipo y cantidad de grasa que se agrega a la carne, esto podría contribuir a una disminución de la obesidad y de enfermedades cardiovasculares. De igual manera, al cultivar carne en un laboratorio, se deben cumplir una serie de normas estrictas respecto a la inocuidad, ya que el cultivo se debe realizar en condiciones estériles, esto reduciría en parte, las enfermedades transmitidas por alimentos. Adicionalmente, el uso de antibióticos que se da en el ganado, ya no sería necesario, disminuyendo los casos de resistencia a los antibióticos en ciertos microorganismos.

Ahora bien, todos estos beneficios están condicionados a las elecciones individuales de cada persona, en cuanto a su alimentación y hábitos.

Incluso se pueden mencionar beneficios ambientales; comparado con la carne proveniente de ganado sacrificado, la agricultora celular requiere $99 \%$ menos terreno, $45 \%$ menos recursos energéticos y $96 \%$ menos emisiones de gas que contribuyen al efecto invernadero.

Todos estos beneficios son importantes, sin embargo, esta tecnología también tiene su lado oscuro. ¿Qué pasaría con todas las pequeñas industrias ganaderas de la actualidad? Miles de personas trabajan actualmente en la industria agrícola, y los investigadores presumen que la agricultura celular, aunque bien podría generar toda una nueva industria, de igual forma, afectaría negativamente la ganadería tradicional.

Ante este tema surgen miles de preguntas, ¿estamos listos para este cambio?, ¿Qué otra implicación tendría el crecimiento de la agricultora celular en nuestras vidas? ¿Qué efectos tiene el consumo de carne sintética? Estas y muchas otras dudas, deben ser analizadas. (Hultin, 2017) (Mattick, 2018)

\section{BIBLIOGRAFÍA}

Hultin, G. (02 de 2017). Lab-Grown Meat: Exploring Potential Benefits and Challenges of Cellular Agriculture. Recuperado el 15 de 01 de 2018, de Food \& Nutrition Magazine: https://foodandnutrition.org/march-april-2017/ lab-grown-meat-exploring-potential-benefits-challenges-cellular-agriculture/ Mattick, C. (08 de 01 de 2018). Cellular agriculture: The coming revolution in food production. BULLETIN OF THE ATOMIC SCIENTISTS, 74(01), 32-35. 


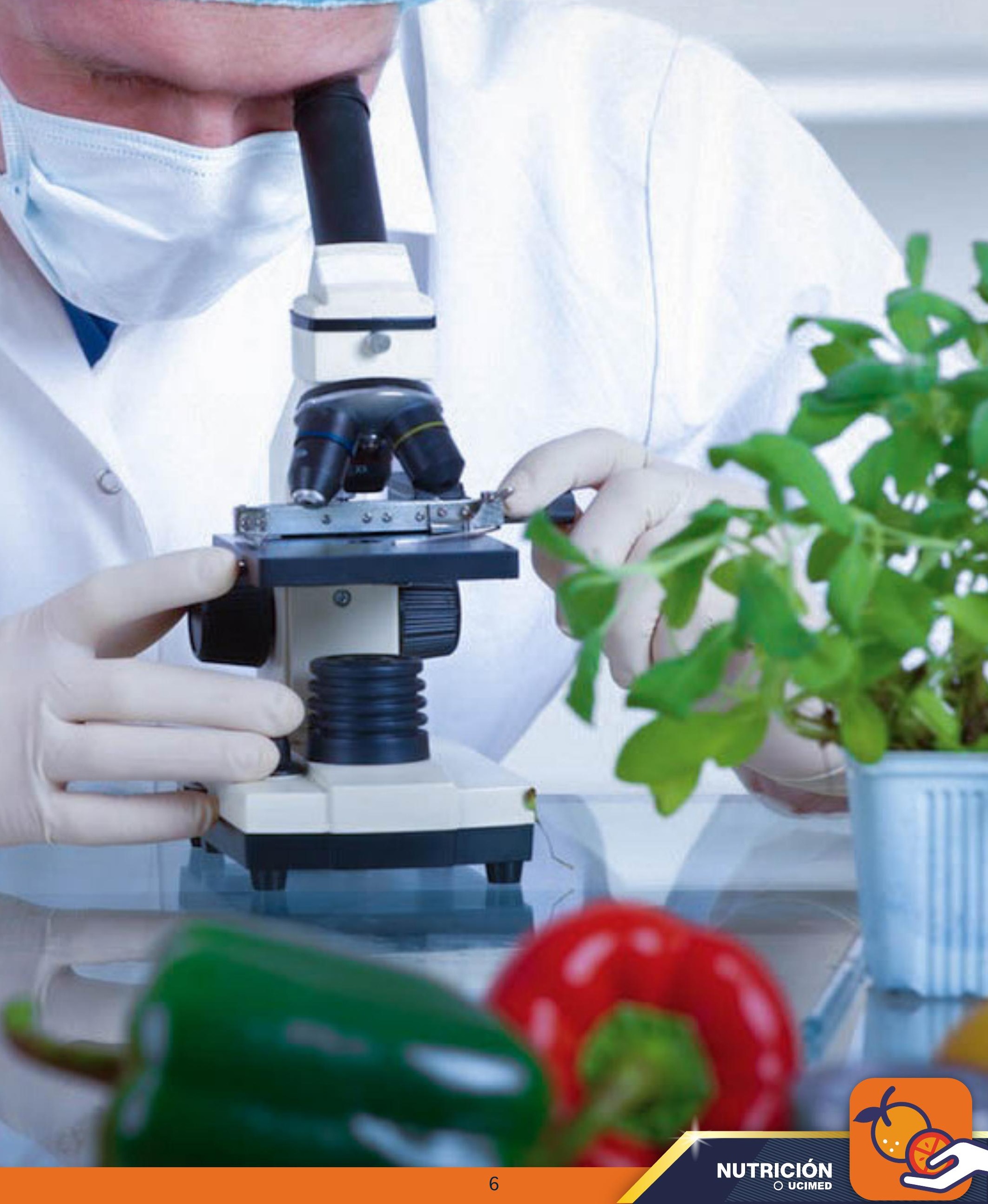

